\title{
Study of Knowledge and Practice of University Females Regarding Reproductive Health and Hygiene in Hail, Saudi Arabia
}

\author{
Rafia Bano*, Fatima Abdullah Al Sabhan*
}

\begin{abstract}
Objectives: Menstruation, although a natural process, is often linked with different types of misconceptions and social taboos, such as treating the menstruating girls as dirty, and not allowing them to discuss the menstruation related problems with other family members. All of this will eventually lead to adverse health outcomes. Keeping these facts in mind the present study was formulated to find out the knowledge and practice of university females in the area of reproductive health and hygiene.

Materials and Methods: The study was carried out using a pretested and modified questionnaire. Leaflets explaining the objectives of the study were distributed in different departments of the university and subjects were invited to participate in the study. After getting an informed consent, those who agreed to fill the questionnaire were included in the study. Data were entered into SPSS-17.0 for the purpose of statistical analysis.

Results: The present study shows mean age at menarche as $12.91 \pm 1.65$ years. $62.5 \%$ of the subjects were aware of the menstrual cycle before their first menarche. Although $80 \%$ of the girls knew that maintaining personal hygiene can prevent problems and pain, only $62 \%$ followed satisfactory routines of hygiene. The overall score for knowledge regarding reproductive health and hygiene was found to be $54 \%$.

Conclusion: Results of the study concluded that menstrual hygiene, as a very important aspect of reproductive health, is often neglected and should be given utmost importance in the education curriculum, especially from the higher secondary levels. However, more research with strong evidences is further needed.
\end{abstract}

Keywords: Menstrual Cycle, Hygiene, Reproduction, Health Knowledge, Practice, Contraceptive Agents, Menarche

\section{Introduction}

It is estimated that around $52 \%$ of the females from all over the world (which approximates to $26 \%$ of the total population) belong to the reproductive age (1). Out of these, almost all females have a regular menstrual cycle each month ranging from two to seven days in duration. Although menstruation is a natural process of the female reproduction, it is always considered as a taboo and people often feel shy to talk about it (2). Due to this reason, it becomes more and more difficult for the girls to follow the hygiene practices which lead to various problems in the society $(3,4)$.

Menstrual hygiene although being a very important factor is often neglected by the Water, Sanitation and Hygiene (WASH) sector and other health care personnel who focus on the knowledge and education of females regarding sexual and reproductive health. Due to this reason, a very large number of women and girls do not have their rights to proper hygiene, health, education, dignity and gender equity. If this situation remains the same, it will be extremely difficult for development programs to reach the target of healthy young generation $(5,6)$.

\begin{abstract}
Impact on health
Menstruation is a natural process of female reproduction, but poor management can result in various health problems. The effect of improper menstrual hygiene on the psychological and social health of females (e.g. stress levels, fear and embarrassment, and social exclusion during menstruation) is also considered as equally important (6). The length of the menstruation period is generally about 28 days but varies from person to person within the range of 21 to 35 days. The menstrual cycle involves ovulation which is the release of female egg into the uterus. In this process tissue and blood vessels start to line the walls of the uterus for the process of fertilization. If the process of fertilization by the sperm does not occur, the preformed lining of the uterus is shed through the vagina along with blood, which results in the monthly menstrual periods $(5,6)$.
\end{abstract}


Sometimes this menstrual cycle is not regular for the first few years after menarche, which is termed as amenorrhea. Dysmenorrhea, or painful menstrual periods are also a common problem during the cycles which include various symptoms such as abdominal pain, nausea and vomiting, general weakness, backache and headache. Due to changing hormonal secretions some of the females may also experience emotional or psychological changes like increased feeling of sadness, irritation or anger. These could start few days before the onset of regular menstrual cycle known as Pre Menstrual Syndrome (PMS), and can be different from one person to another or from one cycle to another (7).

There are different beliefs or myths relating to menstruation in different cultures. Almost in all parts of the world and in each society, people believe that there are different practices to manage the monthly periods and to interact with the menstruating female. Due to this reason the girls become shy and hesitate to take part in the society, which automatically will make their lives difficult and make them restricted $(6,7)$.

Various health issues need to be discussed in this area of research, as they are linked with health risks if improper menstrual hygiene is followed. It is often found that there is a lack of evidence on how much the reproductive hygiene is related to health risks and there is a need for further research from various parts of the world, including a country like Saudi Arabia, where there is lack of available literature regarding this very important aspect of female health (6).

Different studies report different degrees of prevalence for dysmenorrhea and often it is found that there is no proper medical reason for that. Researchers from different parts of the world concluded that dysmenorrhea is common in around $53 \%$ of females between the ages of 16-54 years with approximately $12 \%$ with dysmenorrhea leading to absence in school or work place $(2,6)$.

The risk of infection including sexually transmitted infection is found to be higher during menstrual periods as mucus collection is dislodged during menstruation and blood passes out of the body through the opening of cervix. This allows the bacteria to pass into the female genital and reproductive organs. Also, during this period the $\mathrm{pH}$ of the female reproductive organs is not acidic which helps the yeast infections to grow $(8,9)$.

It is well known that highest percentage of HIV and Hepatitis B are found in blood, therefore this is the high risk period for transferring a high number of blood borne infections including HIV and Hepatitis, especially if the persons are having unsafe sex $(10,11)$.

Some Reproductive Tract Infections (RTIs) can also lead to the risk of other reproductive health problems. Although not proven by scientific researches, it is sometimes found that the bacteria causing Bacterial Vaginosis (BV) is also linked with increased chances of getting HIV. It is also believed that BV can also increase the possibility of some birth related problems such as premature delivery, infections after delivery, and complications after caesarian section or miscarriage $(12,13)$.

All these risk factors clearly indicate that maintaining good personal hygiene during menstruation is of utmost importance. Unfortunately, there is lack of research regarding the health risk factors concerning hygiene practices during menstruation, especially in the developing countries.

It is a well known fact that poor menstrual hygiene will lead to the risk of all reproductive tract infections with studies done in different parts of the world. Keeping all these facts in mind the following study was formulated with an objective to find out the knowledge and practices regarding reproductive health and hygiene, among the university females, in Hail city of Saudi Arabia.

\section{Materials and Methods}

The present study was done in Hail University, Kingdom of Saudi Arabia (KSA), in the College of Applied Medical Sciences. The study was carried out during academic session 2013. Leaflets explaining the objectives of the study were distributed in different departments of the university and subjects were invited to participate in the study. After getting an informed consent, those who agreed to fill the questionnaire were included in the study. Subjects were randomly selected from all the classes and departments. Questionnaire was utilized for the purpose of data collection, which has been pilot tested on a small sample of students ( 10 students) prior to data collection. It was modified according to the results of pilot study. Final questionnaire was given to a total of 130 subjects of which 120 completed questionnaires were analyzed after correction of error. General information was collected from each participant that included age, height, weight, Body Mass Index (BMI), marital status and the number of children. Hemoglobin estimation was done using electronic hemometer. Weight, BMI and other in body measurements such as total minerals, proteins in the body and percent body fat were done using In-Body 720 machine (Bio space, Korea). Other part of the questionnaire included questions related to the history of menarche, pattern of menstrual cycle like duration of bleeding, days of cycle, amount of flow (i.e. heavy or normal), the presence and severity of dysmenorrhea and the presence of PMS.

The second part of the questionnaire included questions related to the complete knowledge regarding various aspects of the menstrual cycle as well as the practices followed during their menstrual periods. The data was coded and entered in the computer for analysis using the SPSS 17.0 Software package. The data was analyzed using descriptive statistics with the help of numbers and percentages, means, SD, and Chi square. ANOVA test was applied to know the significant difference for means of scale variables. The results were checked at 0.05 level of significance. 


\section{Results}

Table 1 represents the general information and history of menstrual cycle. Results of the study show that 24 (20\%) of the subjects were married and $96(80 \%)$ were unmarried. Out of the married participants, 12 (50\%) got married between the ages of $19-21$ years. Four (17\%) of the girls were married at the tender age of 12-14 years, whereas $33 \%$ got married between the ages of $22-24$ years. Out of all married participants, majority $(\mathrm{N}=13,54 \%)$ did not have any children, 7 (29\%) had only 1 child and $4(17 \%)$ had 2 children.

The age of first menstrual period was found to be highly variable ranging from 9 years to 16 years with $12.91 \pm 1.65$

Table 1. General information and history of menstrual cycle

\begin{tabular}{|c|c|c|c|}
\hline Variables & Category & Number & $\%$ \\
\hline \multirow{4}{*}{$\begin{array}{l}\text { Age (yrs) } \\
N=120\end{array}$} & $18-20$ & 58 & 48 \\
\hline & $21-23$ & 47 & 40 \\
\hline & $24-26$ & 11 & 9 \\
\hline & $30-40$ & 4 & 3 \\
\hline \multirow{2}{*}{$\begin{array}{l}\text { Marital status } \\
\mathrm{N}=120\end{array}$} & Married & 24 & 20 \\
\hline & Unmarried & 96 & 80 \\
\hline \multirow{3}{*}{$\begin{array}{l}\text { Age at marriage (yrs) } \\
N=120\end{array}$} & $12-14$ & 4 & 17 \\
\hline & $19-21$ & 12 & 50 \\
\hline & $22-24$ & 8 & 33 \\
\hline \multirow{3}{*}{$\begin{array}{l}\text { Parity } \\
N=120\end{array}$} & 0 & 13 & 54 \\
\hline & 1 & 7 & 29 \\
\hline & 2 & 4 & 17 \\
\hline \multirow{3}{*}{$\begin{array}{l}\text { Age at menarche } \\
N=120\end{array}$} & $9.5-11.5$ & 25 & 20.8 \\
\hline & $11.5-13.5$ & 48 & 40.0 \\
\hline & $13.5-16$ & 47 & 39.2 \\
\hline \multirow{2}{*}{$\begin{array}{l}\text { Anemia } \\
\mathrm{N}=120\end{array}$} & Present & 22 & 18.3 \\
\hline & Absent & 98 & 81.7 \\
\hline \multirow{5}{*}{$\begin{array}{l}\text { Body Mass Index } \\
\mathrm{N}=120\end{array}$} & Underweight & 8 & 6.7 \\
\hline & Normal & 53 & 44.2 \\
\hline & Overweight & 37 & 30.8 \\
\hline & Obese I & 14 & 11.7 \\
\hline & Obese II & 8 & 6.7 \\
\hline \multirow{3}{*}{$\begin{array}{l}\text { Length of menstrual cycle } \\
\mathrm{N}=120\end{array}$} & $<25$ days & 85 & 70.8 \\
\hline & 25-30 days & 29 & 24.2 \\
\hline & $>30$ days & 6 & 5.0 \\
\hline \multirow{3}{*}{$\begin{array}{l}\text { Duration of bleeding } \\
N=120\end{array}$} & $<7$ days & 95 & 79.2 \\
\hline & 7-10 days & 23 & 19.2 \\
\hline & >days & 2 & 1.7 \\
\hline \multirow{4}{*}{$\begin{array}{l}\text { Dysmenorrhea } \\
\mathrm{N}=120\end{array}$} & Absent & 15 & 12.5 \\
\hline & Mild & 31 & 25.8 \\
\hline & Moderate & 45 & 37.5 \\
\hline & Severe & 29 & 24.2 \\
\hline \multirow{2}{*}{$\begin{array}{l}\text { Pre-menstrual syndrome } \\
\mathrm{N}=120\end{array}$} & Present & 114 & 95 \\
\hline & Absent & 6 & 5 \\
\hline
\end{tabular}

years as mean. Almost equal number of normal and late matures $[\mathrm{N}=48(40 \%)$ and $\mathrm{N}=47(39.2 \%)$, respectively] were found. Mild anemia was found in $18.3 \%$ cases.

Assessing the BMI revealed that 53 (44.2\%) had a normal BMI and 37 (30.8\%) were overweight. The percentage of girls in the category of obese I and obese II was 11.7 and $6.7 \%$, respectively. Information on the history of menstrual cycle concluded that only 29 (24.2\%) of the subjects had a normal length of cycle (i.e. 25-30 days), and around $85(71 \%)$ had a menstrual cycle length of less than 25 days. Duration of bleeding was found to be normal in 75 (79.2\%) girls. Twenty three girls (19.2\%) had bleeding for 7-10 days and 2 (1.7\%) were found with dysfunctional uterine bleeding (i.e. more than 10 days of bleeding). A relatively high number i.e. 105 (87.5\%) of the subjects had varying degrees of dysmenorrhea, and a very high percentage (95\%) was suffering from PMS.

Table 2 shows the knowledge of the participants regarding the different aspects of the menstrual cycle. Results from the table show that $75(62.5 \%)$ of the participants were aware of the menstrual cycle before their first menarche. This figure represents a good percentage, and may be due to better awareness among the population. On the other hand, 45 (37.5\%) girls were ignorant about this phenomenon of the reproductive age. The source of information regarding different aspects of reproductive health and

Table 2. Knowledge related to the menstrual cycle

\begin{tabular}{|c|c|c|c|}
\hline Variables & Responses & Number & $\%$ \\
\hline \multirow{2}{*}{$\begin{array}{l}\text { Awareness of menstruation } \\
\text { before menarche }\end{array}$} & Yes & 75 & 62.5 \\
\hline & No & 45 & 37.5 \\
\hline \multirow{5}{*}{ Source of information } & Mother & 57 & 47.5 \\
\hline & Sister & 22 & 18.3 \\
\hline & Friend & 20 & 16.7 \\
\hline & School & 20 & 16.7 \\
\hline & Media & 1 & 0.8 \\
\hline \multirow{4}{*}{ Reaction to first menarche } & Scared & 65 & 54.2 \\
\hline & Irritated & 26 & 21.7 \\
\hline & Normal & 27 & 22.5 \\
\hline & No reaction & 2 & 1.6 \\
\hline \multirow{2}{*}{$\begin{array}{l}\text { What is the normal length } \\
\text { of menstrual cycle? }\end{array}$} & Correct & 26 & 21.6 \\
\hline & Incorrect & 94 & 78.3 \\
\hline \multirow{2}{*}{$\begin{array}{l}\text { What is the correct age of } \\
\text { menarche }\end{array}$} & Correct & 78 & 65 \\
\hline & Incorrect & 42 & 35 \\
\hline \multirow{4}{*}{$\begin{array}{l}\text { Know the cause of } \\
\text { menstruation }\end{array}$} & $\begin{array}{l}\text { Physiological/ } \\
\text { hormonal }\end{array}$ & 88 & 73.3 \\
\hline & Disease & 1 & 0.8 \\
\hline & Any other & 3 & 2.6 \\
\hline & Don't know & 28 & 23.3 \\
\hline \multirow{3}{*}{$\begin{array}{l}\text { Know the organ of the } \\
\text { menstruation }\end{array}$} & Uterus & 98 & 81.7 \\
\hline & Bladder & 10 & 8.3 \\
\hline & Don't know & 12 & 10.0 \\
\hline
\end{tabular}


hygiene was highest from mothers (47.5\%), followed by sisters (18.3\%), friends and school (16.7\%) each and lastly media $(0.8 \%)$. On assessing the reaction to first menarche, results of the study concluded that about 65 (54\%) girls were scared on getting their first menarche, around 18.3 (22\%) were irritated, and 27 (22.5\%) had a normal reaction probably because they knew about the menstrual cycle earlier before their first menarche.

Results of the Table 2 show that only 26 (21.6\%) of the participants gave correct answer regarding the knowledge of the normal length of menstrual cycle. Fortunately 78, i.e. more than half of the subjects had known the right age of menarche (11.5-13.5 years). Eighty eight (73\%) of the subjects knew the cause of menstruation, and about $82 \%$ had the knowledge of the organ of menstrual blood. This represents a good degree of awareness. On the other hand, $23 \%$ of the subjects did not have knowledge of the cause of menstrual bleeding.

Table 3 represents the knowledge and practices related to menstrual hygiene. It is clear from the table that majority of the study participants $(98.3 \%)$ used only readymade sanitary napkins as the absorbent material during their menstrual periods. Remaining 1.7\% used other materials such as homemade cotton pads.

Results of the study concluded that 96 subjects (80\%) had the knowledge that overall personal hygiene especially during the monthly periods can prevent pain and infections. In spite of the large percentage of girls being aware of this fact, only $10(8.3 \%)$ girls took bath daily. On the other hand, 24 girls (20\%) were found with the habit of bathing only after their periods were over. The frequency of cleaning external genitalia during menstruation was found to be satisfactory, among around 74 (62\%) of the subjects.
On analyzing different restrictions placed on the girls during their menstrual cycles, it was revealed that a significantly high percentage of girls $(50.8 \%)$ had no restrictions on them. Nineteen $(15.8 \%)$ girls had religious restrictions, 17 (14.2\%) girls reported that they did not do any physical exercise, $6(5 \%)$ were not allowed to participate in house work and $2(1.7 \%)$ girls were not allowed to attend family functions. Results of the study also found that $15(12.5 \%)$ of the participants were not able to attend the college due to either painful periods or heavy bleeding during menstruation.

Table 4 represents the knowledge of the study participants in different areas related to pregnancy, contraception, transmission routes of AIDS/Sexually Transmitted Diseases (STD), etc. It was concluded from the results that a very few (23\%) of the participants had the correct knowledge of the time of the cycle when a women is most likely to conceive (i.e. fertility periods). Whereas, 78 (65\%) had the idea that the first sign of pregnancy is missed period. When questioned about the correct time to start breast feeding, $41.7 \%$ girls told that it should be started soon after the delivery. However, $45.8 \%$ girls felt that it should be started after 1-2 days, and $12.5 \%$ girls said that breast feeding should be initiated only after 2-3 days have passed. Regarding the use of supplements during pregnancy, only $31.7 \%$ of the subjects had the correct knowledge that iron, calcium and folic acid all are important supplements to be taken during pregnancy.

As far as the knowledge of the use of contraceptives was concerned, less than half of the study population i.e. 56 (46.7\%) had known what actually contraceptives are. And only $20(16.7 \%)$ had ever used contraceptive pills. No other method of contraception was found to be prevalent among the married women except two, who sometimes

Table 3. Practices related to menstrual hygiene

\begin{tabular}{|c|c|c|c|}
\hline Variables & Response & Number & $\%$ \\
\hline \multirow{2}{*}{ Absorbent material used during the menstrual cycle } & Sanitary napkins & 118 & 98.3 \\
\hline & Others & 2 & 1.6 \\
\hline \multirow{2}{*}{ Know that personal hygiene can prevent problems and pain } & Yes & 96 & 80.0 \\
\hline & No & 24 & 20.0 \\
\hline \multirow{3}{*}{ Frequency of bathing during the menstrual cycle } & Daily & 10 & 8.3 \\
\hline & After $1-2$ days & 86 & 71.7 \\
\hline & Only after periods are over & 24 & 20.0 \\
\hline \multirow{2}{*}{ Frequency of cleaning external genitalia } & $>$ or $=3$ times/day & 74 & 61.7 \\
\hline & $0-1$ times/day & 46 & 38.3 \\
\hline \multirow{6}{*}{ Restrictions during the menstrual cycle } & Religious restrictions & 19 & 15.8 \\
\hline & Physical exercise & 17 & 14.2 \\
\hline & College absenteeism & 15 & 12.5 \\
\hline & House work & 6 & 5.0 \\
\hline & Attending family functions & 2 & 1.7 \\
\hline & No restrictions & 61 & 50.8 \\
\hline
\end{tabular}


Table 4. Knowledge related to pregnancy, contraception, AIDS/STD

\begin{tabular}{|c|c|c|c|}
\hline Variables & Responses & Number & $\%$ \\
\hline \multirow{2}{*}{ Knowledge of the time of conception } & Correct answer & 28 & 23 \\
\hline & Wrong answer & 92 & 77 \\
\hline \multirow{2}{*}{ First sign of pregnancy is missed period } & Yes & 78 & 65 \\
\hline & No & 42 & 35 \\
\hline \multirow{3}{*}{ Correct time to start breast feeding } & Soon after delivery & 50 & 41.7 \\
\hline & After $1-2$ days & 55 & 45.8 \\
\hline & After 2-3 days & 15 & 12.5 \\
\hline \multirow{5}{*}{ What supplements should be used during pregnancy } & Iron & 9 & 7.5 \\
\hline & Calcium & 2 & 1.7 \\
\hline & Folic acid & 9 & 7.5 \\
\hline & All & 38 & 31.7 \\
\hline & Don't know & 62 & 51.7 \\
\hline \multirow{2}{*}{ Knowledge of contraceptives } & Yes & 56 & 46.7 \\
\hline & No & 64 & 53.3 \\
\hline \multirow{3}{*}{ Have you ever used contraceptive methods } & Pills & 20 & 16.7 \\
\hline & Traditional methods & 2 & 1.7 \\
\hline & No & 98 & 81.7 \\
\hline \multirow{3}{*}{ Reasons for using contraceptive pills } & Don't want child & 9 & 40 \\
\hline & Convenient to use & 3 & 14 \\
\hline & Due to health reason & 8 & 36 \\
\hline \multirow{8}{*}{ What are the different transmission routes of STD/AIDS } & Mother to child & 14 & 11.7 \\
\hline & Unsafe sex & 78 & 65.0 \\
\hline & Breast feeding & 2 & 1.6 \\
\hline & Blood transfusion & 36 & 30 \\
\hline & Non sterile needles & 20 & 16.6 \\
\hline & Touching and kissing & 5 & 4 \\
\hline & Mosquitoes & 7 & 5.8 \\
\hline & Don't know & 31 & 25.8 \\
\hline \multirow{5}{*}{ How can you avoid STD/AIDS } & Respect religious traditions & 65 & 54 \\
\hline & Don't share sharp objects (like blades and needles) & 15 & 12.5 \\
\hline & Avoid extramarital sex & 37 & 30.8 \\
\hline & Have only one partner & 20 & 16.6 \\
\hline & Don't know & 37 & 30.8 \\
\hline
\end{tabular}

used the traditional methods.

On assessing the different reasons for using contraceptives, $40 \%$ of the subjects who had ever used any method of contraception told that they did not want a child. Fourteen percent told that they found it convenient to use and $36 \%$ used it for medical or health conditions.

Analysis of the knowledge of participants with respect to the different ways of catching STD or AIDS, maximum number of girls i.e. 78 (65\%) answered that it is spread by unsafe sex, followed by blood transfusion $(\mathrm{N}=36,30 \%)$, non-sterile needles $(\mathrm{N}=20,16.6 \%)$, and lastly mother to child $(\mathrm{N}=14,11.7 \%)$. Few girls gave wrong answers like breast feeding $(\mathrm{N}=2,1.6 \%)$, touching and kissing $(\mathrm{N}=5$, $4 \%)$ and mosquitoes $(\mathrm{N}=7,6 \%)$ as the means of spreading STDs and AIDS. Around 31 (26\%) girls did not know the answer (Figure 1).

Regarding the ways to avoid STD and AIDS, a largest percentage of the subjects (54\%) replied that they should respect religious traditions. Approximately 37 (31\%) told that premarital sex should be avoided, 20 (16.6\%) had the opinion that one should have only one partner and $15(12.5 \%)$ felt that sharp objects should not be shared. Whereas, 37 (30.8\%) of the subjects were not aware of the correct answers (Figure 2).

Table 5 shows the mean differences in different study variables according to the marital status of the participants. All the variables except for the hemoglobin level were found to significantly different for married and unmarried groups.

It is very clear from the table that the mean BMI of the 


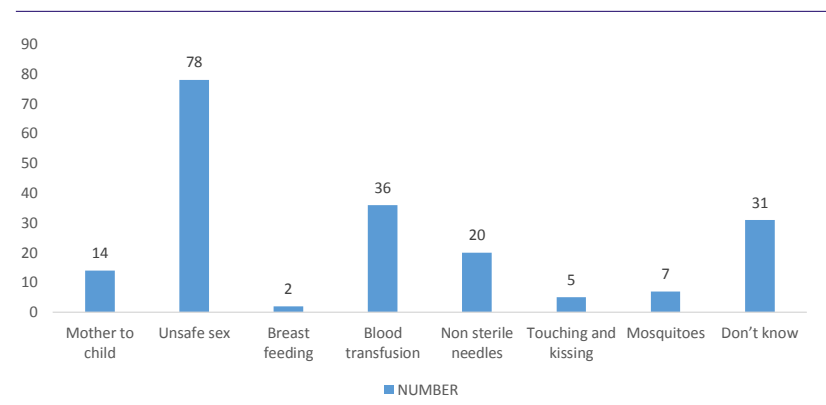

Figure 1. Responses on transmission routes of STD/AIDS

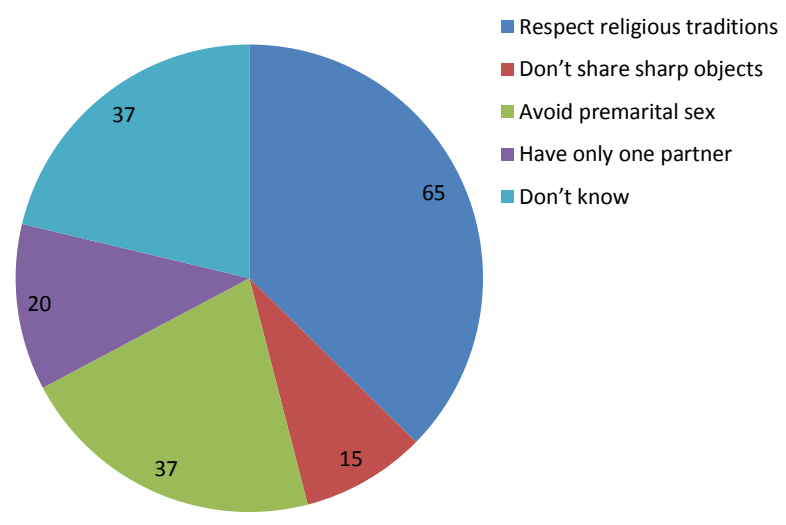

Figure 2. Responses on ways to avoid STD/AIDS married girls was significantly higher $(28.8 \pm 5.8)$ than the mean BMI of unmarried girls (24.5 \pm 4.8$)$. Also the mean percent body fat of the married subjects was higher than that of the unmarried ones ( 43.1 vs. $38.5, \mathrm{P}=0.015)$. The difference between the mean visceral fat and total body protein was also found to be highly significant $(\mathrm{P}=0.000$; Table 5). The age of first menstrual period was found to be $12.91 \pm 1.65$ years with $12.2 \pm 1.8$ years for married and $13.07 \pm 1.5$ years for unmarried subjects.

On analyzing the total score for the knowledge of reproductive health and related areas, it was observed that the married participants got a significantly higher mean score $(8.52 \pm 2.23,57 \%)$ as compared to the unmarried study group $(7.97 \pm 2.01,53 \%)$. The total knowledge score for both the groups combined was $8.08 \pm 2.05$ (54\%), which is unfortunately a low level.

Table 6 shows the differences in the mean study variables according to the age of the study participants. The table clearly shows that all the mean values except hemoglobin level shows a steady increase with increasing age with statistically significant difference $(\mathrm{P}<0.05)$.

Analysis of mean knowledge score regarding the different areas of reproductive health and hygiene shows that it is lowest $(7.56,50 \%)$ for $18-20$ years, followed by $21-23$ years $(7.94,53 \%)$, then $24-26$ years $(9.02,60 \%)$ and the highest for $30-40$ years $(10.0,67 \%)$ showing a very high level of statistical significance $(\mathrm{P}=0.000)$.

Table 5. ANOVA for mean difference in the study variables according to the marital status

\begin{tabular}{lcccc}
\hline Variables & \multicolumn{2}{c}{ Marital status } & P value & Total mean \\
\cline { 2 - 4 } & $\mathbf{N}=\mathbf{2 4}$ & $\mathbf{N}=\mathbf{9 6}$ & 0.000 \\
BMI & $28.8 \pm 5.8$ & $24.5 \pm 4.8$ & 0.806 \\
Hemoglobin level & $12.7 \pm 1.4$ & $12.8 \pm 1.3$ & 0.015 \\
Percent body fat & $43.1 \pm 10.2$ & $38.5 \pm 7.4$ & 0.000 & 0.000 \\
Visceral fat & $119.4 \pm 40.2$ & $89.8 \pm 31.6$ & 0.04 & $12.91 \pm 1.65$ \\
Total protein & $1.17 \pm 0.38$ & $1.66 \pm 0.47$ & 0.025 & $8.08 \pm 2.05$ \\
Total minerals & $1.13 \pm 0.34$ & $1.34 \pm 0.47$ & 0.024 \\
Age at menarche & $12.2 \pm 1.8$ & $13.07 \pm 1.5$ & \\
Knowledge score & $8.52 \pm 2.23(57 \%)$ & $7.97 \pm 2.01(53 \%)$ & & \\
\hline
\end{tabular}

Table 6. Mean differences in the study variables according to age

\begin{tabular}{|c|c|c|c|c|c|c|}
\hline \multirow{2}{*}{ Variables } & \multicolumn{4}{|c|}{ Age (years) } & \multirow{2}{*}{ Total mean } & \multirow{2}{*}{$P$ value } \\
\hline & $18-20$ & $21-23$ & $24-26$ & $30-40$ & & \\
\hline BMI & $24.28 \pm 5.6$ & $25.15 \pm 4.8$ & $28.37 \pm 2.1$ & $30.45 \pm 0.0$ & $25.32 \pm 5.3$ & 0.031 \\
\hline $\mathrm{Hb}$ level & $12.76 \pm 1.4$ & $12.71 \pm 1.2$ & $13.09 \pm 1.2$ & $12.75 \pm 0.0$ & $12.80 \pm 1.2$ & 0.305 \\
\hline Percent body fat & $37.03 \pm 9.4$ & $39.13 \pm 6.3$ & $46.16 \pm 2.1$ & $46.50 \pm 0.0$ & $39.35 \pm 8.2$ & 0.013 \\
\hline Visceral fat & $86.66 \pm 35.1$ & $90.20 \pm 28.8$ & $125.71 \pm 17.7$ & $153.95 \pm 0.0$ & $95.5 \pm 35.3$ & 0.000 \\
\hline Score & $\begin{array}{c}7.56 \pm 1.99 \\
(50 \%)\end{array}$ & $\begin{array}{c}7.94 \pm 1.92 \\
(52.9 \%)\end{array}$ & $\begin{array}{c}9.02 \pm 0.70 \\
(60.03 \%)\end{array}$ & $\begin{array}{c}10.0 \pm 0.0 \\
(66.6 \%)\end{array}$ & $8.08 \pm 2.1$ & 0.000 \\
\hline
\end{tabular}




\section{Discussion}

The mean age of first menstrual period was found to be 12.91 years with the maximum number of girls i.e. 48 (40\%) attaining menarche between the ages of 11.5-13.5 years. Some similar studies conducted by other researchers in other parts of the globe show similar mean menarcheal ages $(14,15)$.

The present study concluded that around $62.5 \%$ of the girls were aware of this natural phenomenon before menarche. Also mothers and sisters were found as the largest source of getting knowledge (47.5\%). In a study by Dasgupta et al., a similar percentage of girls (62.7\%) had known about menstruation before their first periods (2). Study by another researcher concluded that $42.5 \%$ urban and $55.4 \%$ rural girls had knowledge about menstruation before getting their first periods (14). In another study done on 664 schoolgirls of 14-18 years, mass media was found as the main source of knowledge regarding hygiene, and then the family (16). Fortunately, here a large percentage (73.3\%) of the participants had known the cause of menstruation, and majority (99\%) used sanitary napkins as the absorbent material during their periods, which shows a good degree of awareness.

Studies from various parts of the world show different restrictions on girls during their menstrual periods. $67 \%$ of the subjects from Nepal and 71\% from West Bengal reported that they cannot attend a religious function. Also $46 \%$ of the Nepalese girls told that they were not allowed to cook during their periods $(17,18)$.

Meanwhile 70\% Afghani, 98\% Gujrati (Indian) and 52\% Iranian girls reported that they do not bathe during their periods. Also $10 \%$ of girls from Nepal, $43 \%$ from West Bengal and $70 \%$ of girls from Afghanistan expressed that they were not allowed to play or exercise (17-19). The present study revealed lack of physical activity or exercise in only $14.2 \%$ of the subjects. On the other hand $11 \%$ of girls from Nepal, 15\% from West Bengal and 15\% from Afghanistan said that they did not have any restrictions placed on them $(17,18)$. In contrast the present study shows a large number $(50 \%)$ of the subjects claiming no restrictions.

Another group of studies show the days missed from school or reduced performance. One research indicates that more than $90 \%$ of girls in Ghana miss school due to monthly periods, whereas in other studies done in Kenya more or less similar number of girls were found absent for a day or more from school. Other studies performed in different parts of the world revealed that around half of girls miss between 1-4 days of school each month due to painful periods or embarrassment and 39\% reported reduced performance. Our study shows only $12.5 \%$ college absenteeism (6).

In regard to dysmenorrhea the present study concluded that a relatively high percentage $(87.5 \%)$ of the studied cases suffered from the condition as compared to studies done in other parts of the world reporting percentages around $71 \%$ and $54 \%$ with different degrees and prevalence of PMS (18).

Studies from different parts of the world claimed the presence of different menstrual hygiene practices and knowledge of menstrual hygiene. Researches conducted in various parts of the world revealed that a majority of girls in the developing and under developed countries do not bathe during their monthly period. Some of them do not even wash and use soap for cleaning their reproductive parts $(18,19)$. In the present study the frequency of bathing daily during the menstrual cycle was found to be only $8.3 \%$, whereas $71.7 \%$ of the girls took bath only after 2-3 days.

When a young girl gets her first monthly period, she could be scared if she is completely ignorant. She could be extremely frightened to see blood coming out of the reproductive organ (20). The young girls should be properly educated and should be made aware of this natural phenomenon before the time to avoid the after effects. In this study $62.5 \%$ of the girls had proper knowledge about menstruation before their first menarche and 54.2\% got scared when they started to menstruate.

Unfortunately, the present study shows the frequency of bathing (90\%) and cleaning external genitalia (38.8\%) to be unsatisfactory. In some other studies also, around half of the population claimed that they were not allowed to take bath during their periods (21).

This study shows only $46.7 \%$ of the subjects had the knowledge of contraceptives and pills were the most commonly used method. On the other hand, results from a study done in India shows that majority of the participants know about the use of birth control pills and sterilization (22), whereas other studies show the use of contraception methods other than the contraceptive pills (23). The present study shows that around $38 \%$ of the girls gave wrong answers regarding the spread of STD/AIDS and were unaware, whereas about $31 \%$ did not know how to avoid these diseases.

\section{Conclusion}

This study was done to assess the knowledge of university females regarding the reproductive health and hygiene. Results of the study concluded that as a whole the girls in this area of Saudi Arabia were unaware of the physiology and processes related to reproductive cycle. It reflected a lot of misconceptions, ignorance and incomplete knowledge.

Earlier studies have demonstrated that proper knowledge prior to menarche and maintaining adequate menstrual hygiene help the girls to manage their problems well. The present study also highlighted that females should have proper knowledge regarding their reproductive health to protect them from any suffering.

It is a well known fact that reproductive health is a very important part of health of an individual in general as it paves way for the health of future generations (24). Re- 
productive health problems should be solved on the first priority basis by focusing on the programs and services responsible for it (25). Each and every individual has the right to enjoy reproductive health and this is possible if the young generation has healthy children, healthy marital relation and happy family.

Menstrual hygiene and management is crucial in ensuring that everyday life is not interrupted by menstruation. It will ensure that you can continue with your normal daily activities such as going to school, going to work or doing household chores. It can also prevent potential situations of embarrassment and in turn, make you feel confident about yourself and your body. In this regard, maintaining proper menstrual hygiene is very important for your well-being and development (26).

For each and every individual reproductive health is equally important all over the world. However for females it is of utmost importance especially due to the process of menstruation. It is also well known that most of the health problems appearing during these younger years, will affect your health condition at a date later in life (26). Comprehensive health education programs especially in the areas of reproductive health and hygiene can provide the required information at the correct age. It will increase the awareness and empower the female youth to protect themselves from STD/AIDS and various other related health problems. Results of the present study revealed that further research is required on the health, and psychosocial impact of menstrual hygiene.

\section{Ethical issues}

All the participants were given an informed consent to keep the information private and confidential. The study was approved in the Department of Clinical Nutrition in the University of Hail.

\section{Conflict of interests}

No conflict of interest was found for this study.

\section{Acknowledgments}

The authors thank all the staff and head of department of clinical nutrition, College of Applied Medical Sciences, University of Hail, Saudi Arabia for their help and cooperation throughout the course of this study. Also, the authors express their sincere thanks to all the participants of this study for their valuable responses.

\section{References}

1. Sowmya H, Singhe MS. Knowledge and practices of reproductive health among school going rural adolescent girls of sullia taluk. Elixir Soc Sci 2012;50:10493-7.

2. Dasgupta A, Sarkar M. Menstrual hygiene: How hygienic is the adolescent girl? Indian J Community Med 2008;33(2):77-80.
3. Population Reference Bureau. The world's women and girls - 2011 data sheet. 2011. Available from: http://www.prb.org/Publications/Datasheets/2011/ worlds-women-and-girls.aspx

4. Zegeye DT, Megabiaw B, Mulu A. Age at menarche and the menstrual pattern of secondary school adolescents in northwest Ethiopia. BMC Womens Health 2009;9:29.

5. Thomas F, Renaud F, Benefice E, de Meeüs T, Guegan JF. International variability of ages at menarche and menopause: Patterns and main determinants. Hum Biol 2001;73(2):271-90.

6. Sarah House S, Mahon T, Cavill S. Menstrual hygiene matters: A resource for improving menstrual hygiene around the world. 1st ed. water aid resources; 2012. p. 22-37.

7. Menstruation-and-religion. Available from: http:// myperiodblog. wordpress.com/2010/11/19

8. McKinley Health Center, Vaginal Discharge; The Board of Trustees of the University of Illinois. 2008. Available from: http://www.mckinley.illinois.edu/ handouts /vaginal_discharge.html

9. Ben-Noun L. What is the biblical attitude towards personal hygiene during vaginal bleeding? Eur J Obstet Gynecol Reprod Biol 2003,106(1):99-101.

10. Reichelderfer PS, Coombs RW, Wright DJ, Cohn J, Burns DN, Cu-Uvin S, et al. Effect of menstrual cycle on HIV-1 levels in the peripheral blood and genital tract. WHS 001 Study Team. AIDS 2000;14(14):101-7.

11. Benki S, Mostad SB, Richardson BA, Mandaliya K, Kreiss JK, Overbaugh J. Cyclic shedding of HIV1 RVA in cervical secretions during the menstrual cycle. J Infect Dis 2004;189(12):192-201.

12. Sommer M. Utilizing participatory and quantitative methods for effective menstrual hygiene management related policy and planning. Paper for the UNICEFGPIA Conference, New York, 2010. Available from: http://www.sswm.info/content/menstrual-hygienemanagement

13. Demba E, Morison L, van der Loeff MS, Awasana AA, Gooding E, Bailey R, et al. Bacterial vaginosis, vaginal flora patterns and vaginal hygiene practices in patients presenting with vaginal discharge syndrome in the Gambia, West Africa. BMC Infect Dis 2005;5:12.

14. Deo DS, Ghattargi CH. Perceptions and practices regarding menstruation: a comparative study in urban and rural adolescent girls. Indian J Community Med 2005;30(1):33-4.

15. Khanna A, Goyal RS, Bhawsar R. Menstrual practices and reproductive problems: a study of adolescent girls in Rajasthan. J Health Manag 2005;7(1):91-107.

16. El-Gilany AH, Badawi K, El-Fedawy S. Menstrual hygiene among adolescent schoolgirls in Mansoura, Egypt. Reprod Health Matters 2005;13(26):147-52.

17. Ministry of Education and Ministry of Public Health, 
Islamic Republic of Afghanistan (2010). Assessment of knowledge, attitude and practice of menstrual health and hygiene in girls schools in Afghanistan. 2007;10(2):89-94.

18. Poureslami M, Osati-Ashtiani F. Attitudes of female adolescents about dysmenorrhoea and menstrual hygiene in Tehran suburbs. Arch Iran Med 2002;5(4):219-24.

19. WaterAid. Menstrual hygiene in South Asia; A neglected issue for WASH (water, sanitation and hygiene) programmes; 2010.

20. CDC, STD treatment guidelines; Evidenced based recommendations for the treatment and prevention of STDs. 2010. Accessed 20 Nov 2014. Available at www.cdc.gov/std/

21. Ali TS, Rizvi SN. Menstrual knowledge and practices of female adolescents in urban Karachi, Pakistan. J Adolesc 2010;33(4):531-41.

22. Bobhate PS, Shrivastava SR. A cross sectional study of knowledge and practices about reproductive health among female adolescents in an urban slum of Mumbai. J Family Reproductive Health 2011;5(4):117-24.

23. De la Ayala-Castellanos MM, Vizmanos-Lamotte B, Portillo-Dávalos RA. [Sexual and reproductive health among adolescents in high school in Guadalajara, México]. Ginecol Obstet Mex 2011;79(2):86-92. [In Spanish].

24. Sadiq N. Reproductive health/family planning and the health of infants, girls and women. Indian J Pediatr 1997;64(6):739-44.

25. United Nations Population Information Network (POPIN) Guidelines on Reproductive Health; UN Population Division, Department of Economic and Social Affairs. Nov. 2011. Available from: http://www. un.org/popin

26. Pullon S, Reinken J, Sparrow M. Prevalence of dysmenorrhoea in Wellington women. $\mathrm{N}$ Z Med J 1988;101(839):52-4.

Copyright $\odot 2014$ The Author(s); This is an open-access article distributed under the terms of the Creative Commons Attribution License (http://creativecommons.org/licenses/by/4.0), which permits unrestricted use, distribution, and reproduction in any medium, provided the original work is properly cited. 